\title{
Genetic profiling of chromosome I in breast cancer: mapping of regions of gains and losses and identification of candidate genes on $\mathrm{lq}$
}

\author{
B Orsetti ${ }^{1,4}$, M Nugoli ${ }^{1,4}$, N Cervera', L Lasorsa', P Chuchana', C Rougé', L Ursule', C Nguyen², F Bibeau ${ }^{3}$, \\ C Rodriguez' and C Theillet*,I
}

'Génotypes et Phénotypes Tumoraux, EMI229 INSERM/Université Montpellier I, Centre de Recherche, CRLC Val D'Aurelle-Paul Lamarque, Montpellier cedex 5 34298, France; '2ERM 206 INSERM/Université Aix-Marseille2, Parc Scientifique de Luminy Marseille, France; ${ }^{3}$ Department of Pathology, CRLC Val D'Aurelle-Paul Lamarque, Montpellier, France

\begin{abstract}
Chromosome I is involved in quantitative anomalies in 50-60\% of breast tumours. However, the structure of these anomalies and the identity of the affected genes remain to be determined. To characterise these anomalies and define their consequences on gene expression, we undertook a study combining array-CGH analysis and expression profiling using specialised arrays. Array-CGH data showed that I p was predominantly involved in losses and I q almost exclusively in gains. Noticeably, high magnitude amplification was infrequent. In an attempt to fine map regions of copy number changes, we defined 19 shortest regions of overlap (SROs) for gains (one at I $\mathrm{p}$ and $\mathrm{I} 8$ at I $\mathrm{q}$ ) and of 20 SROs for losses (all at Ip). These SROs, whose sizes ranged from I70 kb to $3.2 \mathrm{Mb}$, represented the smallest genomic intervals possible based on the resolution of our array. The elevated incidence of gains at I q, added to the wellestablished concordance between DNA copy increase and augmented RNA expression, made us focus on gene expression changes at this chromosomal arm. To identify candidate oncogenes, we studied the RNA expression profiles of 307 genes located at I q using a home-made built cDNA array. We identified 30 candidate genes showing significant overexpression correlated to copy number increase. In order to substantiate their involvement, RNA expression levels of these candidate genes were measured by quantitative (Q)-RT-PCR in a panel of 25 breast cancer cell lines previously typed by array-CGH. Q-PCR showed that II genes were significantly overexpressed in the presence of a genomic gain in these cell lines, and 20 overexpressed when compared to normal breast.
\end{abstract}

British Journal of Cancer (2006) 95, |439- |447. doi:I0.1038/sj.bjc.6603433 www.bjcancer.com

Published online 24 October 2006

(c) 2006 Cancer Research UK

Keywords: array-CGH; amplicon; oncogene; profiling

Chromosome 1 is recurrently altered in a number of human malignancies. In solid tumours, structural aberrations include several recurrent chromosomal translocation sites, as well as frequent gains or losses involving either chromosomal arm (Struski et al, 2002; Teixeira et al, 2002). In breast cancer, chromosome 1 is the site of rare stereotypic rearrangements; isochromosome $\mathrm{i}(1)(\mathrm{q} 10)$, and $\operatorname{der}(1 ; 16)(\mathrm{q} 10 ; \mathrm{p} 10)$ (Tsarouha et al, 1999). More significantly, it has been shown, by either LOH or CGH work, to be frequently involved in copy number changes (CNCs) (Kerangueven et al, 1997; Osborne and Hamshere, 2000). Fifty to $60 \%$ of breast tumours analysed by CGH presented gains at $1 \mathrm{q}$, whereas the short arm showed predominantly losses, except the 1 p31-p32 region which presented occasional gains (Courjal and Theillet, 1997; Tirkkonen et al, 1998). Gains at 1q frequently affect the whole arm; however, a number of tumours or cell lines exhibit

\footnotetext{
*Correspondence: Dr C Theillet; E-mail: theillet@valdorel.fnclcc.fr

${ }^{4}$ These authors contributed equally to this work.

Received 8 June 2006; revised 6 September 2006; accepted 25 September 2006; published online 24 October 2006
}

interstitial gains sometimes reduced to a chromosomal band or sub-band (Courjal and Theillet, 1997; Larramendy et al, 2000). These data suggesting the existence at $1 \mathrm{q}$ of several regions of gains were thus concordant with $\mathrm{LOH}$ studies, indicating the occurrence of at least four regions of allelic imbalance in breast tumours (Kerangueven et al, 1997). Because gains at 1q were observed both in low- and high-grade breast tumours, its implication in early stages of disease development has been shown (Tirkkonen et al, 1998; Cummings et al, 2000). Recent data using BAC-based array-CGH on independent sets of breast tumours have confirmed the frequent nature of gains on chromosome 1 , as well as the existence of multiple cores of amplification (Stange et al, 2006).

Altogether, these data suggested the presence of several important cancer genes on chromosome 1. Several known oncogenes (NRAS, JUN, MYCL, TAL1, BLYM, LCK) map on chromosome 1q, but their implication in breast cancer has remained elusive, whereas genes like MUC1 and PLU-1/JARIB1 were proposed as candidates (Bieche et al, 1997; Lu et al, 1999). However, it seems clear that most genes involved remain to be identified. This notion was reinforced by recent expression 
profiling studies in breast tumours that showed that 25 genes located on the long arm of chromosome 1 showed increased expression levels in conjunction to DNA copy number increase (CNI) (Hyman et al, 2002).

Our goal in this work was to determine more precisely the boundaries of regions of chromosome 1 showing CNCs in breast tumours and gain insight on genes involved. To achieve this, we built a genomic array covering both arms of chromosome 1 at an average density of one BAC clone/ $0.85 \mathrm{Mb}$ and analysed 30 breast cancer cell lines and 30 primary breast tumours by array-CGH. Based on the array-CGH profile, we defined shortest regions of overlap (SROs) of copy number gain or loss. A total of 20 regions of loss, all located at chromosome $1 \mathrm{p}$, and 19 regions of gain, one at $1 \mathrm{p}$ and 18 at $1 \mathrm{q}$, were defined. Because gains at $1 \mathrm{q}$ were found in over $60 \%$ of the analysed samples and increased copy number are clearly related to augmented gene expression, we focused our expression study on the identification of candidate genes at 1q. To this aim, we studied expression profiles of 307 known genes located on the long arm of chromosome 1. Using a supervised analysis method, we selected 30 genes showing significantly increased RNA expression in relation to genomic gains. RNA expression levels of 28 out of 30 genes were verified by quantitative (Q) - RT-PCR and the overexpression in relation to gains was confirmed for 11 out of 28 genes, whereas 20 out of 28 showed overexpression compared to normal breast.

\section{MATERIALS AND METHODS}

\section{Tumours and blood samples}

Thirty breast tumours were obtained from the Pathology Department at the Val d'Aurelle Cancer Center of Montpellier (France). Tumour biopsies were snap-frozen in liquid nitrogen upon surgical removal and stored at $-80^{\circ} \mathrm{C}$ until DNA and RNA extraction. Tumour cohort was composed of $63.7 \%$ invasive ductal carcinoma, $18 \%$ invasive lobular carcinoma, $15 \%$ invasive adenocarcinoma of unspecified type and $3.3 \%$ other types of carcinomas of the breast. The mean age of patients was 58 years. Tumours were mostly grade 2 and 3 (46.7 and $29.2 \%$, respectively), whereas $13.9 \%$ were grade 1 and $10 \%$ were uninformed.

\section{Cell lines and tumours}

Breast cancer cell lines used in this study included BRCAMZ01, MDAMB175, MDAMB453 (D Birnbaum, INSERM U119, Marseille, France), CAL51, MDAMB435, SKBR7, ZR7530 (P Edwards, Department of Pathology, Cambridge, UK), BT474, MCF7Rich (F Vignon, INSERM U540, Montpellier, France), HS578T, MDAMB436, (A Puisieux, INSERM U590, Lyon, France), SUM149, SUM185, SUM52 (S Ethier, University of Michigan, Ann Arbor, MI, USA), EFM19, (DSMZ, Braunschweig - Germany), BT20, BT483, HCC1187, HCC1395, HCC1428, HCC1937, HCC1954, HCC2218, MDAMB157, MDAMB361, MDAMB468, SKBR3, T47D, UACC812 and ZR751 (ATCC, American Type Culture Collection, Manassas, VA, USA). All cell lines were cultured as recommended by suppliers.

\section{Genomic arrays}

We built a genomic array covering chromosomes 1, 8 and 17. Coverage of chromosomes 8 and 17 has been described by Orsetti et al (2004) and Gelsi-Boyer et al (2005). Chromosome 1 was covered by 257 BAC clones selected as follows: 225 BAC clones from the Barbara Trask collection (CHORI) http://www.ncbi.nlm. nih.gov/genome/cyto/hbrc.shtml and 32 clones selected according to their cytogenetic position and content in genetic markers. Clones were arranged according to the human genome freeze of April 2003. This resulted in an average density of one clone/
$0.85 \mathrm{Mb} \pm 0.95 \mathrm{Mb}$. However, clone distribution was uneven and thus could produce local variations in resolution (a complete list of BAC clones with precise coordinates is available in Supplementary Table S1).

Arrays were produced according to the following procedure. BAC, PAC and Cosmid DNA were isolated using Nucleobond BAC100 from Macherey-Nagel (Hoerdt, France). Probe DNA to be spotted was prepared by DOP-PCR amplification on $10 \mathrm{ng}$ of BAC matrix DNA in a final reaction volume of $100 \mu$ l. Primer sequences and DOP-PCR protocol used are available on the Sanger Center web site (http://www.sanger.ac.uk/HGP/methods/cytogenetics/ DOPPCR.shtml) (Orsetti et al, 2004). We performed this with slight modifications: the second round DOP-PCR primer was not aminolinked. Purification of PCR products was carried out using Nucleofast 96 PCR plates (Macherey-Nagel, Hoerdt, France). Purified PCR products were re-suspended in dd $\mathrm{H}_{2} \mathrm{O}$ at $2 \mu \mathrm{g} \mu \mathrm{l}^{-1}$. An aliquot was run on an agarose gel in order to ascertain even distribution of the product in all the wells. Prior spotting products were diluted $1: 1$ in spotting solution (GE-Healthcare, Orsay, France) and spotted in quadriplicate onto Corning GapsII slides (Schiphol-Rijk, The Netherlands) using a Lucidea array spotter IV (Amersham Biosciences, Orsay, France).

\section{Array-CGH probe labelling, hybridisation, image capture and data analysis}

Genomic DNA was digested by NdeII according to the supplier's recommendations (Roche Diagnostics, Meylan, France). Three hundred nanograms of digested genomic DNA was labelled by random priming in a $50 \mu \mathrm{l}$ reaction containing $0.02 \mathrm{mM}$ dATP, $0.02 \mathrm{~mm}$ dGTP, $0.02 \mathrm{~mm}$ dTTP, $0.05 \mathrm{~mm}$ dCTP, $0.04 \mathrm{~mm}$ Cy3-dCTP or Cy5-dCTP, $25 \mathrm{U}$ of Klenow Fragment $\left(50 \mathrm{U} \mu \mathrm{l}^{-1}\right.$, New England Biolabs, Ozyme, Saint Quentin Yvelines, France), $10 \mathrm{~mm}$ mercaptoethanol, $5 \mathrm{mM} \mathrm{MgCl}_{2}, 50 \mathrm{~mm}$ Tris-HCL (pH 6.8) and $300 \mu \mathrm{g} \mathrm{ml}^{-1}$ random octamers. The reaction was incubated at $37^{\circ} \mathrm{C}$ for $20 \mathrm{~h}$ and stopped by adding $2.5 \mu \mathrm{l}$ EDTA $0.5 \mathrm{M} \mathrm{pH} 8$. The reaction product size was about $100 \mathrm{bp}$. We purified labelled products using microcon 30 filters (Amicon, Millipore, Molsheim, France). Abundance of the labelled DNA was checked using a spectrophotometer and incorporation of dyes was calculated using Molecular Probes software (http://www.probes.com/resources/ calc/basedyeratio.html). A mix of 700 pmol Cy5- and $700 \mathrm{pmol}$ Cy3-labelled probes was ethanol-precipitated in the presence of $250-300 \mu \mathrm{g}$ of human Cot-1 DNA (Roche Diagnostics, Meylan, France) and $100 \mu \mathrm{g}$ herring sperm DNA (Promega, Charbonnières, France). The pellet was dried and re-suspended in $110 \mu \mathrm{l}$ Hybrisol VII (Appligene Oncor, Qbiogen, Illkirch, France). The probes were denatured at $80^{\circ} \mathrm{C}$ for $10 \mathrm{~min}$, and repetitive sequences were blocked by pre-annealing at $37^{\circ} \mathrm{C}$ for $30 \mathrm{~min}$.

Slide processing was performed using a HS4800 hybridisation station (Tecan, Lyon, France). Slides were treated with a blocking buffer $(5 \times$ SSC, $0.2 \%$ SDS, $1 \%$ BSA $)$ at $42^{\circ} \mathrm{C}$ for $30 \mathrm{~min}$ and washed three times at $42^{\circ} \mathrm{C}$ using $2 \times$ SCC, $0.2 \%$ SDS. Preannealed probes were injected in the chambers and hybridisation took place at $37^{\circ} \mathrm{C}$ for $16 \mathrm{~h}$ with mild agitation. Post-hybridisation washes were as follows: three washes at $52.5^{\circ} \mathrm{C}$ in solution $1(2 \times$ SSC, $0.2 \%$ SDS $)$, followed by three washes in solution $2(0.5 \times$ SSC, $0.2 \%$ SDS $)$ and one wash in solution $3(0.1 \times$ SSC $)$ at $52.5^{\circ} \mathrm{C}$. To remove salt and detergent residues, a brief wash with dd water was performed at $37^{\circ} \mathrm{C}$ and slides were dried within the chambers by an injection of $\mathrm{N}_{2}$ at $30^{\circ} \mathrm{C}$.

Arrays were scanned by a GenIII Array Scanner (Amersham Biosciences, Orsay, France). Images were analysed by ARRAYVISION 6.0 software (Amersham Biosciences, Orsay, France). Spots were defined by use of the automatic grid feature of the software and manually adjusted when necessary. Fluorescence intensities of all spots were then calculated after subtraction of local background. These data were then analysed using a custom 
made MS-Excel VBA script. Cy3 and Cy5 global intensities were normalised with the entire set of spots on the array, Cy3/Cy5 ratios were calculated, each BAC clone was spotted in four replicates, the median values of replicate spots were calculated and these values were used to define the selection threshold for individual spots. Only replicates showing less than $15 \%$ of deviation from the median were kept and a clone was taken into consideration when at least three of four replicates showed values within the $15 \%$ deviation limit. Representation of profiles with $\log 2$ ratios in $Y$ axis and $\mathrm{Mb}$ position of clones (http://genome.ucsc.edu, April 2003 freeze) along the chromosome in $X$-axis. For each sample, at least two experiments were performed (Cy3/Cy5 and Cy5/Cy3), and the final profile corresponds to the mean of two experiments.

\section{RNA expression profiling of chromosome 1q using cDNA arrays}

Variations in gene expression levels were analysed by large-scale measurement with home-made cDNA mini-arrays $(7.5 \times 9 \mathrm{~cm} ; 720$ human genes; 11 genes $\mathrm{cm}^{-2}$ ) produced as described (Nugoli et al, 2003). More specifically, our mini-arrays comprised 319 ESTs corresponding to 307 known genes mapping at $1 \mathrm{q}$ (Supplementary Table S2). Selection of cDNA clones was performed according to information gathered (and crosschecked) from different webbased databases; Genemap: http://www.ncbi.nlm.nih.gov/genemap99/, Genecards: http://genecards.weizmann.ac.il/, Genelynx: http://www.genelynx.org/ or UCSC Genome Browser, release April 2003: http://genome.ucsc.edu/. Hybridisation signals were quantified using the HDG Analyzer software (Genomic Solutions, Ann Arbo, MI, USA) by integrating all spot pixel signal intensities and removing spot background values determined in the neighbouring area.

\section{Quantitative RT - PCR}

RNAs from cell lines and normal breast samples used for real-time PCR were isolated using the RNeasy Minikit (Qiagen, France) in accordance with the supplier's conditions. $1 \mu \mathrm{g}$ of total RNA, treated beforehand with RNase-free DNase (Promega, France), was reverse-transcribed using the SuperScript II RT and $250 \mathrm{ng}$ of random hexamers (Invitrogen, France). Q-PCR reactions were carried out in an ABI Prism 7000 instrument (Applied Biosystems, France) in a final volume of $15 \mu \mathrm{l}$ according to the supplier's recommendations using SYBR Green as a detector. Primers were as described in Supplementary Table S3 in the supplementary data. We designed the primers for 17 genes, with the assistance of the Primer Express software (Applied Biosystems, France), and for the remaining 14 we used the Quantitect Primer Assays from the Gene Globe database (Qiagen, France). ESRRG primers were as described by Ariazi et al (2002). Standard curves were determined for each gene analysed by the use of serial dilutions from the same pool of cDNAs. Relative quantities were calculated referring to these curves and relative expression levels of each target gene was normalised to $28 \mathrm{~S}$ RNA.

\section{Identification of aberrantly expressed genes in regions of CNC}

We applied a supervised analysis scheme to identify genes significantly correlated to CNCs. Sample selection was based on array-CGH profiles. For each consensus region, samples presenting at least $25 \%$ of the BACs included in the region with $\log 2$ ratio exceeding 0.25 were considered as amplified. For each available gene at 1q, we computed a discriminating score (DS) by comparing expression levels between the subgroup of samples presenting amplification (subgroup 1) and the subgroup of samples without amplification (subgroup 2). Discriminating score (Golub et al, $1999)$ was defined as $\mathrm{DS}=(\mathrm{M} 1-\mathrm{M} 2) /(\mathrm{S} 1+\mathrm{S} 2)$, where $\mathrm{M} 1$ and $\mathrm{S} 1$ represent mean and the s.d. of expression levels of one gene in subgroup 1, M2 and S2 in subgroup 2. Confidence levels were calculated by performing 1200 iterative random permutations per gene as described previously (Bertucci et al, 2004). Significance threshold for expression differences was DS $\geqslant 0.32$ corresponding to $<0.01$ false positive. For Q-PCR results, we applied a $t$-test analysis.

\section{RESULTS}

\section{Patterns of gains and losses at chromosome 1 in breast cancer}

We analysed genomic profiles of 30 primary tumours and 30 cancer cell lines by array-CGH using a home-built array covering chromosome 1 at an average density of one clone $/ 0.85 \mathrm{Mb}$, with some local variations resulting in higher density locally at 1q. All cell lines studied, preselected on the basis of classical CGH profiles, presented gains and/or losses at either 1p or 1q. Array-CGH profiles were in good concordance with classical CGH data, confirming the prevalence of losses on the short arm combined with gains at 1q. However, in contrast to classical CGH data, gains encompassing the whole $1 \mathrm{q}$ were rare, with profiles typically showing multiple subregions of gains (Figure 1 and Supplementary Figure S1). Most prevalent gains were at $1 \mathrm{q} 21-\mathrm{q} 22,1 \mathrm{q} 23-\mathrm{q} 24$, $1 \mathrm{q} 32$ and $1 \mathrm{q} 42-\mathrm{q} 44$, whereas losses were noticeably rare on the long arm (Figures 1 and 2). On average, tumours and cell lines presented $1-3$ regions of gains per sample (Figure 1).

Our aim was to define the cores of the different regions of CNC on chromosome 1 and thus, it was important to determine their boundaries. Correspondingly, we delineated the SROs involved in either gains or losses on the whole chromosome 1 . We overlaid all the array-CGH profiles and searched for shortest overlaps shared by at least six independent tumours or cell lines. We defined 19 SROs of gains (one at $1 \mathrm{p}$ and 18 at $1 \mathrm{q}$ ) and 20 SROs of losses (all at $1 \mathrm{p}$ ) whose sizes ranged from $170 \mathrm{~kb}$ to $3.2 \mathrm{Mb}$ (Figure 1). Precise locations and BAC content are described in Supplementary Data (Table S4). However, it must be pointed out that the actual sizes of these regions of overlap may change according to the resolution of the array used to define them.

Although, gains were generally of low-to-moderate level, high magnitude amplifications were observed. Similarly, we observed high magnitude losses (Figure 1). We were interested to see whether high magnitude amplifications occurred at recurrent sites and, accordingly, defined seven peaks of amplification, which all, except that at $1 \mathrm{p} 12$, matched with SROs (Figure 1). This discrepancy can be explained by the different criteria used to define peaks of amplification and SROs. Whereas SROs required to be shared by at least six samples to be retained, peaks of amplification needed to occur in at least three tumours or cell lines.

\section{Identification of candidate genes involved in CNCs at $1 \mathrm{q}$}

Because the relation between genomic gains and increased RNA expression is well established and linked to a selective advantage for cancer cells, we concentrated our efforts on the identification of the genes showing significantly increased expression levels as a consequence of gains at 1q. To this mean, we analysed RNA expression profiles of 307 genes located on chromosome 1q in 29 cell lines and 26 tumours using self-made cDNA arrays. We performed a supervised analysis aiming at selecting genes differentially expressed in tumours or cell lines presenting a gain. We formed groups of tumours and cell lines according to their 'gain' or 'no gain' status in each region. However, based on the 19 SROs, this resulted in a large number of subclasses whose samples were too small to reach statistical significance. To obviate this problem we defined larger regions of gains, designated consensus 

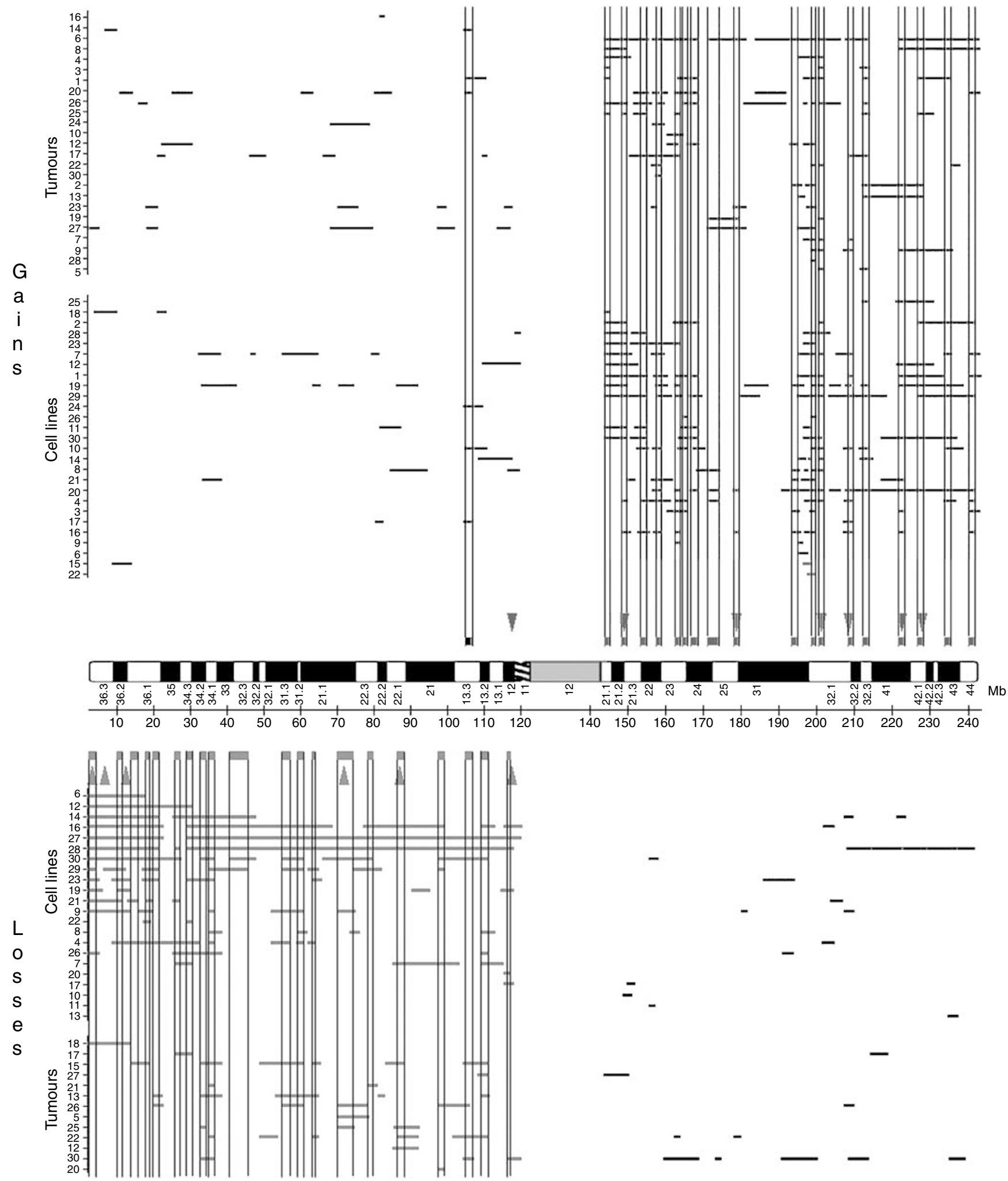

Figure I Profiles of gains and losses on chromosome I in breast cancer. Definition of SROs and events of high magnitude. Grey horizontal lines represent regions of gains (top) or losses (bottom) observed in each tumour or cell line (minimum two BACs involved with a log 2 ratio $\geqslant 0.25$ or $\leqslant-0.25$ ). Shortest regions of overlap are indicated as bold grey bars with gains above the chromosome ideogram and losses below. Shortest regions of overlap correspond to the smallest overlap shared by at least six tumours or cell lines. Arrow heads indicate events of high magnitude, either peaks of amplification or loss. They corresponded to events with $\log 2$ ratio $>0.7$ in at least three tumours or cell lines. Code for cell lines I: BRCAMZ0 I, 2: BT20, 3: BT474, 4: BT483, 5: CAL5I, 6: EFMI9, 7: HCCI 187, 8: HCCI 395, 9: HCCI 428, I0: HCCI 937, I I: HCCI 954, I2: HCC22 18, I3: Hs578T, I 4: MCF7Rich, I 5: MDAMB I57, I 6: MDAMB I75, 17: MDAMB361, I8: MDAMB435, 19: MDAMB436, 20: MDAMB453, 21: MDAMB468, 22: SKBR3, 23: SKBR7, 24: SUM52, 25: SUMI 49, 26: SUMI85, 27: T47D, 28: UACC8I2, 29: ZR75I and 30: ZR7530. Code for primary tumours I: VAI593, 2: VA4055, 3: VA4380, 4: VA4390, 5: VA4435, 6: VA4956, 7: VA5033, 8: VA5077, 9: VA5 I01, 10: VA5410, II: VA5450, 12: VA6088, 13: VA6190, 14: VA6204, 15: VA6219, 16: VA6277, 17: VA6582, 18: VA6586, 19: VA6660, 20: VA7079, 21: VA7106, 22: VA7417, 23: VA6052, 24: VA6094, 25: VA6138, 26: VA6143, 27: VA6270, 28: VA6403, 29: VA6603 and 30: VA7072. 


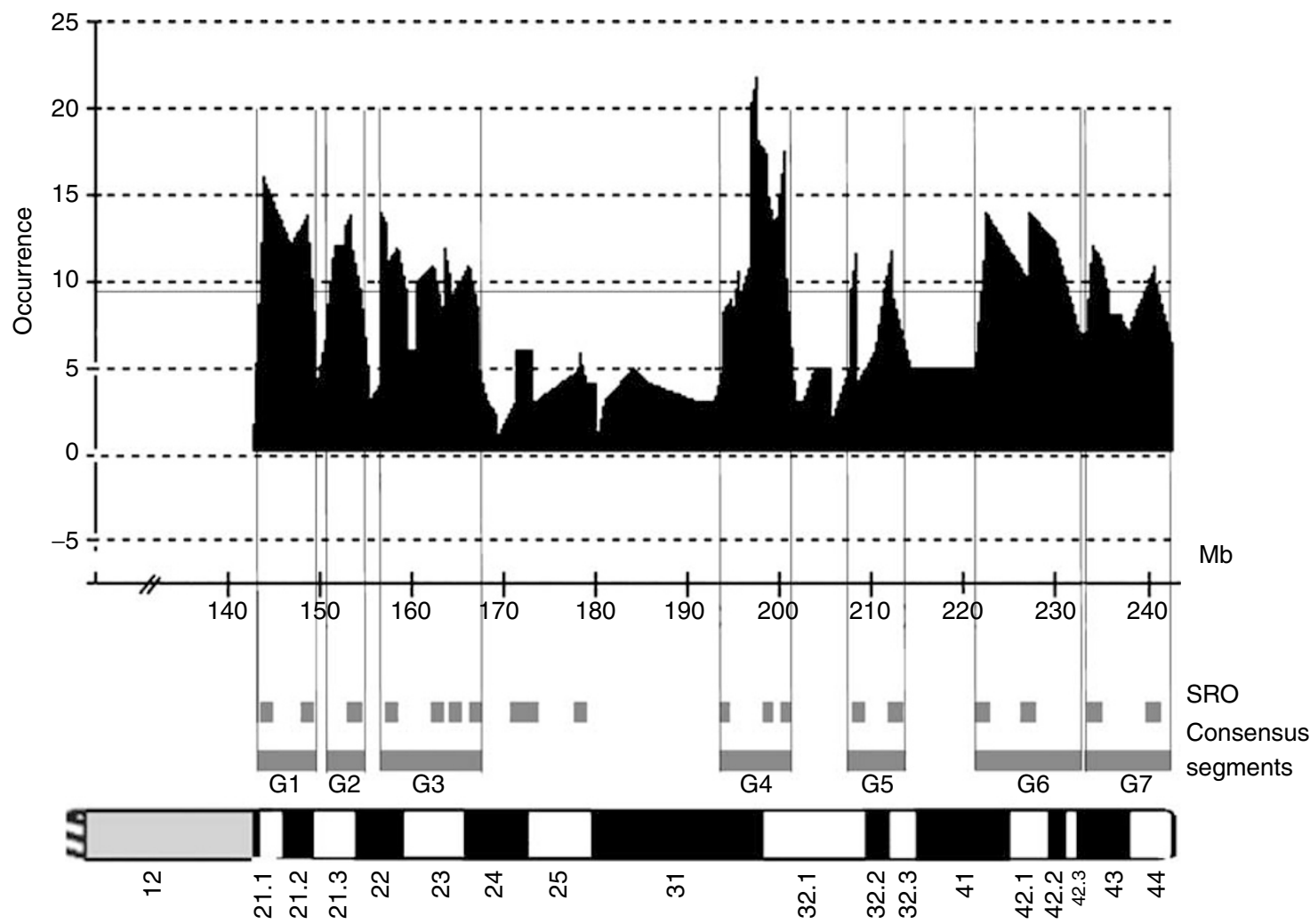

Figure 2 Definition of consensus regions of gain at Iq. Consensus regions were based on the curve of cumulated occurrence of gains (log 2.ratio $\geqslant 0.25$ ) at lq in 30 cell lines and 30 primary tumours. Low points defined boundaries and high points possible cores. Only regions showing an occurrence exceeding the mean (9.0) were considered. Plots are based on the Mb positioning of the clones on the array. Hence, clones positioned close to each other may appear as merged. Consensus regions of gains were designated GI through G7 and represented as bold grey lines. Short grey lines represent the position of SROs relative to that consensus regions.

Table I Description of consensus regions of gain at lq

\begin{tabular}{|c|c|c|c|c|c|c|c|}
\hline & $\begin{array}{l}\text { Consensus } \\
\text { segments }\end{array}$ & Genomic positions & Size (bp) & Cytoband & BAC names & SRO included & $\begin{array}{c}\text { Number of genes } \\
\text { on our array }\end{array}$ \\
\hline Gl & $\begin{array}{l}\text { Start } \\
\text { End }\end{array}$ & $\begin{array}{l}|43| 547 \mid 8 \\
148346294\end{array}$ & 5191576 & $\begin{array}{l}\mid q 21.1 \\
\mid q 21.3\end{array}$ & $\begin{array}{l}\text { CTD-2122124 } \\
\text { RPII-74Cl }\end{array}$ & $2-3$ & 31 \\
\hline $\mathrm{G} 2$ & $\begin{array}{l}\text { Start } \\
\text { End }\end{array}$ & $\begin{array}{l}150842537 \\
154512266\end{array}$ & 3669729 & $\begin{array}{l}\text { |q21.3 } \\
\text { |q23.| }\end{array}$ & $\begin{array}{l}\text { RPII-73Cl0 } \\
\text { RPII-9Ig5 }\end{array}$ & 4 & 36 \\
\hline G4 & $\begin{array}{l}\text { Start } \\
\text { End }\end{array}$ & $\begin{array}{l}194594372 \\
201998427\end{array}$ & 7404055 & $\begin{array}{l}\mid \mathrm{q} 31.3 \\
\mid \mathrm{q} 32.1\end{array}$ & $\begin{array}{l}\text { RPII-32IMI3 } \\
\text { CTD-22I8h7 }\end{array}$ & $11-12-13$ & 33 \\
\hline G5 & $\begin{array}{l}\text { Start } \\
\text { End }\end{array}$ & $\begin{array}{l}208699401 \\
213910793\end{array}$ & 5211392 & $\begin{array}{l}\text { Iq32.3 } \\
\text { |q4| }\end{array}$ & $\begin{array}{l}\text { RPII-2I6fl } \\
\text { RPII-260al0 }\end{array}$ & $14-15$ & 8 \\
\hline
\end{tabular}

$\mathrm{BAC}=$ bacterial artificial chromosome; $\mathrm{SRO}=$ shortest region of overlap. Consensus regions of gain were defined by the BAC bording them, Mb start corresponds to the $5^{\prime}$ end of the proximal $\mathrm{BAC}, \mathrm{Mb}$ end to the $3^{\prime}$ end of the distal BAC.

regions, which encompassed several SROs. To do this, we determined the occurrence curve for gains at each target clone at 1q. We reasoned that ruptures and low points in the curve represented the boundaries of the different regions (Figure 2). We retained only the events whose occurrence exceeded the mean (horizontal bar on Figure 2) and boundaries were defined by vertical lines tangential to the occurrence curve. Seven consensus regions of gains (G1 through G7), ranging from 3.6 to $11 \mathrm{Mb}$ and encompassing two to three SROs on average were defined at $1 \mathrm{q}$ (Table 1 and Figure 2). Gains located between 170 and $180 \mathrm{Mb}$ were 
not considered because their occurrence was below the threshold. Of the 307 genes studied, 178 genes were located within the consensus regions of gains defined at 1q. To identify genes whose expression levels were significantly modified in relation to CNC, we calculated the DS followed by 1200 random permutations (gain $v s$ no gain) and our significance threshold for expression differences was $D S \geqslant 0.32$ corresponding to $<0.01$ false positive. This resulted in the selection of 30 genes distributed in consensus regions G1 through G7 (Table 2). Interestingly, we noted that a number of the selected genes were located in close vicinity to each other suggesting the existence of local clusters, possibly related to the existence of core regions of gain.

\section{Candidate gene verification by $\mathrm{Q}-\mathrm{RT}-\mathrm{PCR}$}

In order to confirm expression profiling results, we measured the RNA expression levels of 28 out of 30 genes by Q-RT-PCR in 25 cell lines typed by array-CGH. The c1orf2 and HNRPU genes could not be studied because of unsuccessful primer design. In addition to the 28 genes selected from the cDNA array data, we studied the recently identified candidate oncogene RAB25 (Cheng et al, 2004), which is located in consensus region $\mathrm{G} 2$, in close vicinity to two of our candidate genes, MAPBPIP and CCT3 (Table 2). A $t$-test analysis revealed that only 5 out of 29 genes showed $P$-values $=<0.05$, indicative of significant expression differences in relation to gains. We reasoned that this may be owing to small sample size (we had to restrict our Q-PCR analysis to the 25 cell lines because tumour RNAs were no more available) and decided to consider genes with $P$-values $=<0.1$. This allowed us to pick out a total of 11 genes (Table 2). It was, however, noticeable that the $R A B 25$ gene was not selected in this test, whereas it was, when we compared mean expression levels in cancer cell lines to that in a series of five normal breast tissues expression ( $t$-test $P$ value $=0.002)$. We, thus, applied this test to the whole set of genes which revealed that 21 out of 29 genes were significantly overexpressed in cancer cell lines compared to normal breast.

\section{DISCUSSION}

Chromosome 1 is a prevalent site of numerical anomalies combining losses on the short arm and gains on the long one in breast carcinomas (Courjal and Theillet, 1997; Teixeira et al, 2002). Gains at $1 \mathrm{q}$ are found in over $50 \%$ of breast tumours. Although being frequent in high-grade breast cancer, they have been related to ER-positive cancers (Rennstam et al, 2003; Loo et al, 2004) and have been suggested to occur early in the natural history of the disease (Buerger et al, 1999; Malamou-Mitsi et al, 1999). These particularities fostered our interest in characterising the genomic regions involved in $\mathrm{CNCs}$ and identifying genes at $1 \mathrm{q}$ whose expression was modified in relation to gains.

Array-CGH data presented here confirm chromosomal CGH results showing the duality on chromosome 1, with the short arm being mainly involved in losses and the long arm almost exclusively in gains. Our data clearly indicated the existence of multiple subregions of losses at $1 \mathrm{p}$ and of gains at $1 \mathrm{q}$. In an attempt to define these subregions with greater precision and possibly delimitate their cores, we determined the SROs for gains (19 SROs) and losses (20 SROs) on chromosome 1, whose sizes ranged from $170 \mathrm{~kb}$ to over $3 \mathrm{Mb}$. Shortest regions of overlap were defined according to the classical $\mathrm{LOH}$ scheme, in order to narrow down genetic intervals encompassing candidate genes. Our data thus suggest that numerical anomalies at chromosome 1 , be it losses or gains, are complex and involve a large number of subregions and possibly combinations of anomalies.

Although losses at $1 \mathrm{p}$ were observed in a sizeable portion of the tumours and cell lines, gains were notably prevalent. This was in full agreement with previous chromosomal CGH results by us and other groups (Courjal and Theillet, 1997; Tirkkonen et al, 1998; Malamou-Mitsi et al, 1999; Larramendy et al, 2000). Interestingly, gains at $1 \mathrm{q}$ were of low-to-moderate level with a lower prevalence of amplifications compared to other chromosomes. Furthermore, no sharp transitions were observed at the boundaries of amplification peaks at $1 \mathrm{q}$, in contrast to chromosomes $8 \mathrm{p}$ or $17 \mathrm{q}$, where such recurrent breakpoint sites were common (Orsetti et al, 2004; Gelsi-Boyer et al, 2005).

The relation between aberrant gene dosage and gene expression is well accepted and is best shown in case of CNI. The common nature of genomic gains (which include DNA amplification) in breast tumours indicates that it is an effective mechanism of positive genetic selection in cancer cells (Upender et al, 2004). By cDNA-array expression profiling, we identified 30 genes whose RNA expression was significantly increased in relation to genomic gains. Overexpression in the presence of genomic gain could be confirmed only for 11 genes by Q-RT - PCR. We suspect that these numbers may be related to the small size of our sample. We had to restrict our $\mathrm{Q}-\mathrm{PCR}$ verification to 25 cell line RNAs, because tumour RNAs were no more available. We noted that 21 genes presented significant overexpression when compared to normal breast, suggesting the involvement of a larger number of genes within our original selection. It was interesting to see that, to the exception of PLU-1/JARID1B (Lu et al, 1999), all the genes identified in our study were newly proposed as candidate cancer genes. Furthermore, MUC1 (Schroeder et al, 2004), a long known cell surface marker overexpressed in a sizeable fraction of breast tumours, and KIF14 (Corson et al, 2005), a recently proposed candidate at 1q31, presented DSs below the threshold and were excluded from our selection. Genes selected in our study belong to rather diverse functional groups, of which three appeared prevalent. The first corresponded to a broad collection of positive regulators of cell proliferation. They include PIP5K1A, MAPBPIP, RAB25A, PCTK3, RAB4 and MPZL1. The second was made of genes whose products were related to transcriptional regulation or chromatin remodelling such as USF1, JARID1B, TBX19 or CROC4. The third included genes involved in cellular trafficking VPS45A, ARF1, LYST, CCT3 or basic cellular metabolism CA14, ALDH9A1. Note that RAB25 has also been related to the activation of protein trafficking between the membrane and the endoplasmic reticulum (Cheng et al, 2005). Similar functional groups have been observed in other selections of genes involved in genomic gains or amplifications, thus indicating the importance of activated transcription, increased signalling and protein trafficking or catabolism in cancer. However, 8 out of 24 overexpressed genes did not belong to any of the above-mentioned functional groups. Although two genes, PDZK1 and MLLT11, were clearly relevant to cancer as both have been proposed as a candidate oncogene in diverse haematological malignancies (Busson-Le Coniat et al, 1999; Inoue et al, 2004; Tse et al, 2004), six were more difficult to relate to cancer. Three corresponded to genetic determinants of genetic syndromes (MTMR, DISC1, MTX1) and the three others bore functions with no obvious link to cancer (NENF, ENSA, TARBP1).

We were interested to verify the concordance between our analysis and the recently described 'Transcriptome Correlation Map' (Reyal et al, 2005), which defined groups of collinear genes showing coordinated expression. Their data set indicated 235 genes presenting a significant Transcriptome Correlation Score (TCS) at 1q, of which 147 mapped within the region of gains defined in our work, of which 72 (48\%) were located in G1 and G2 (1q21 or 1q22). Genes within consensus regions of gains presented a significantly higher TCS, thus being in accordance with the existence of a link between increased expression and copy number gains at 1q. This was further corroborated by the fact, that 14 out of $30(43 \%)$ genes selected by DS showed significant TCS, which is an increase compared to the 55 out of $178(31 \%)$ genes common to both studies and located in the regions of gains. This suggested an 
Table 2 Gene expression analysis at Iq and correlation with copy number gain

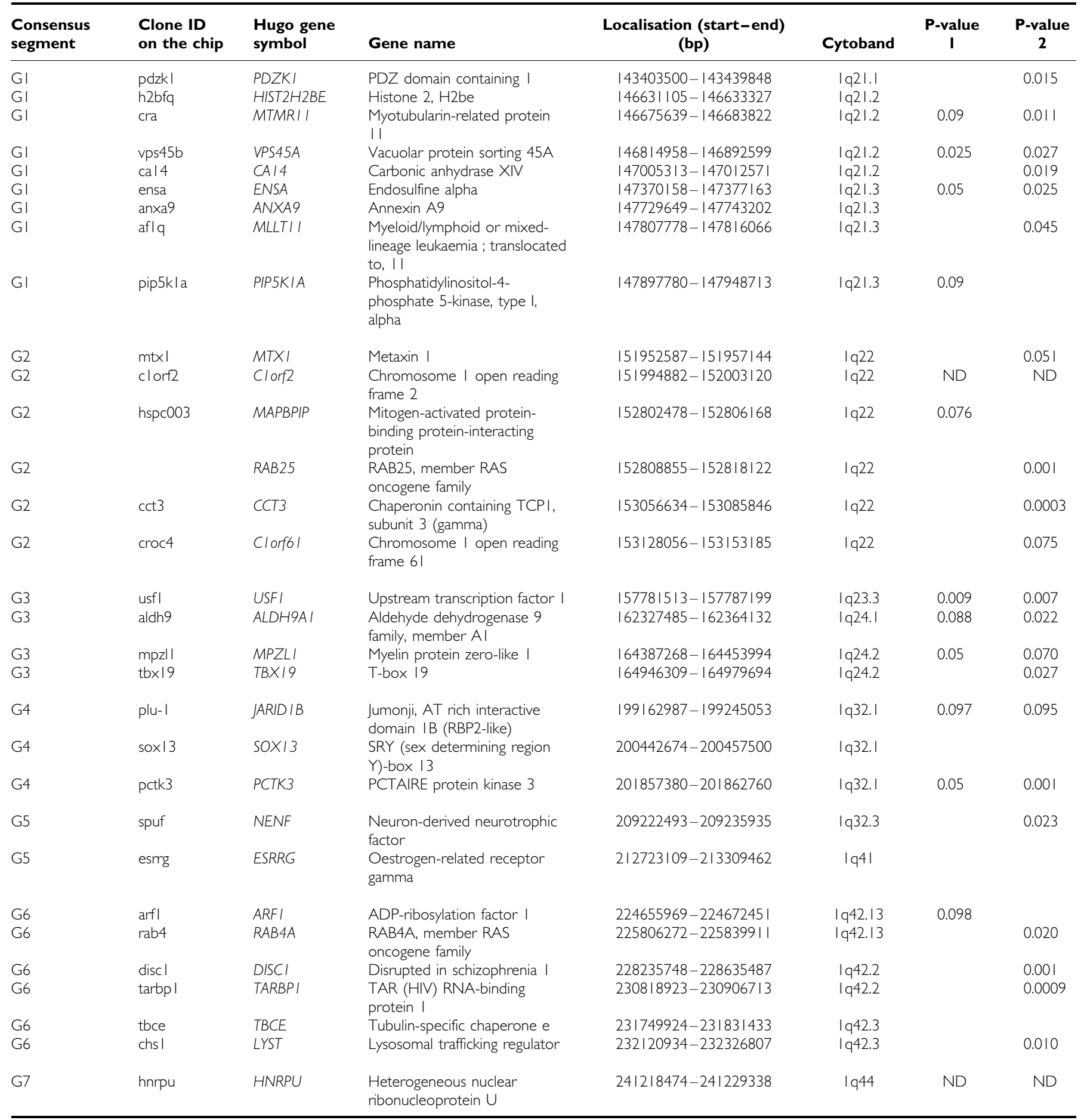

$\mathrm{ND}=$ not done and refers to $\mathrm{Q}-\mathrm{RT}-\mathrm{PCR}$ measurements which could not be performed. RNA expression profiles of 307 genes located at I q were analysed in a total of 29 breast cancer cell lines and 26 primary tumours. Genes presented correspond to the 30 genes selected by DS. Significance threshold was DS $>0.32$ corresponding to $<0.0$ I false positive. Expression levels were quantified by Q-RT-PCR for 28 out of 30 genes (primer design was unsuccessful for cl orf2 and HNRPU). Quantitative PCR primer sequences are presented in Supplementary Table S2. The recently reported candidate oncogene RAB25, which was not present on our array, was quantified as a positive control. Quantitative RT-PCR data were analysed for differential expression using two $t$-test approaches; $t$-test I (noted $P$-value I) indicates correlation with copy number gain; $t$-test 2 ( $P$-value 2) differential expression with normal breast. Two significance thresholds were used; strict $P=<0.05$, tolerant $P=<0.1, P$-values $>0.1$ were considered as nonsignificant and only values within the tolerance limit are indicated. Cell lines analysed were: BRCAMZ0I, MDAMBI75, CAL5I, MDAMB435, SKBR7, ZR7530, BT474, MCF7Rich, HS578T, MDAMB436, SUMI49, SUMI85, BT20, HCCI 187, HCCI428, HCCI937, HCCI954, HCC22I8, MDAMBI57, MDAMB36I, MDAMB468, SKBR3, T47D, UACC8I2 and ZR75I. 
enrichment of genes belonging to the transcriptome correlation map in our set of candidate genes at $1 \mathrm{q}$ and contrasted to our previous findings at $8 \mathrm{p}$ (Gelsi-Boyer et al, 2005).

Despite their frequent nature, numerical anomalies affecting chromosome 1 in breast and other cancers have drawn less attention than deserved. Most studies focussed on specific subregions or candidate genes. In this work, we characterised at high-resolution regions recurrently involved in copy number alterations on chromosome 1 in breast cancer and identified 24 candidate genes overexpressed in regions of gains at 1q. To our knowledge, this is the first study mapping at high-resolution regions of loss and gain on the whole length of chromosome 1 and proposing a series of candidate genes affected by CNCs. Further work will need to ascertain the true relevance to breast cancer of these candidate genes. This will require bioclinical and functional studies. Moreover, as our screen was based on a set of 307 known genes representing $40-50 \%$ of the genes assigned at 1q, our selection leaves way to the identification of additional candidate genes.

\section{REFERENCES}

Ariazi EA, Clark GM, Mertz JE (2002) Estrogen-related receptor alpha and estrogen-related receptor gamma associate with unfavorable and favorable biomarkers, respectively, in human breast cancer. Cancer Res 62: $6510-6518$

Bertucci F, Finetti P, Rougemont J, Charafe-Jauffret E, Nasser V, Loriod B, Camerlo J, Tagett R, Tarpin C, Houvenaeghel G, Nguyen C, Maraninchi D, Jacquemier J, Houlgatte R, Birnbaum D, Viens P (2004) Gene expression profiling for molecular characterization of inflammatory breast cancer and prediction of response to chemotherapy. Cancer Res 64: $8558-8565$

Bieche I, Ruffet E, Zweibaum A, Vilde F, Lidereau R, Franc B (1997) MUC1 mucin gene, transcripts, and protein in adenomas and papillary carcinomas of the thyroid. Thyroid 7: 725-731

Buerger H, Otterbach F, Simon R, Poremba C, Diallo R, Decker T, Riethdorf L, Brinkschmidt C, Dockhorn-Dworniczak B, Boecker W (1999) Comparative genomic hybridization of ductal carcinoma in situ of the breast-evidence of multiple genetic pathways. J Pathol 187: $396-402$

Busson-Le Coniat M, Salomon-Nguyen F, Hillion J, Bernard OA, Berger R (1999) MLL-AF1q fusion resulting from $t(1 ; 11)$ in acute leukemia. Leukemia 13: 302 - 306

Cheng KW, Lahad JP, Gray JW, Mills GB (2005) Emerging role of RAB GTPases in cancer and human disease. Cancer Res 65: 2516-2519

Cheng KW, Lahad JP, Kuo WL, Lapuk A, Yamada K, Auersperg N, Liu J, Smith-McCune K, Lu KH, Fishman D, Gray JW, Mills GB (2004) The RAB25 small GTPase determines aggressiveness of ovarian and breast cancers. Nat Med 10: 1251 - 1256

Corson TW, Huang A, Tsao MS, Gallie BL (2005) KIF14 is a candidate oncogene in the $1 \mathrm{q}$ minimal region of genomic gain in multiple cancers. Oncogene 24: $4741-4753$

Courjal F, Theillet C (1997) Comparative genomic hybridization analysis of breast tumors with predetermined profiles of DNA amplification. Cancer Res 57: $4368-4377$

Cummings MC, Aubele M, Mattis A, Purdie D, Hutzler P, Hofler H, Werner M (2000) Increasing chromosome 1 copy number parallels histological progression in breast carcinogenesis. Br J Cancer 82: 1204-1210

Gelsi-Boyer V, Orsetti B, Cervera N, Finetti P, Sircoulomb F, Rouge C, Lasorsa L, Letessier A, Ginestier C, Monville F, Esteyries S, Adelaide J, Esterni B, Henry C, Ethier SP, Bibeau F, Mozziconacci MJ, CharafeJauffret E, Jacquemier J, Bertucci F, Birnbaum D, Theillet C, Chaffanet M (2005) Comprehensive profiling of 8p11-12 amplification in breast cancer. Mol Cancer Res 3: 655-667

Golub TR, Slonim DK, Tamayo P, Huard C, Gaasenbeek M, Mesirov JP, Coller H, Loh ML, Downing JR, Caligiuri MA, Bloomfield CD, Lander ES (1999) Molecular classification of cancer: class discovery and class prediction by gene expression monitoring. Science 286: $531-537$

Hyman E, Kauraniemi P, Hautaniemi S, Wolf M, Mousses S, Rozenblum E, Ringner M, Sauter G, Monni O, Elkahloun A, Kallioniemi OP,

\section{ACKNOWLEDGEMENTS}

The authors wish to thank Pr Philippe Jeanteur for constant help and support, Annick Causse for excellent technical help. This study was supported by funds from INSERM, the Association de Recherche sur le Cancer (ARC), grant 5102, the Ligue Nationale de Lutte Contre le Cancer (LNCC), as part of the 'Carte d'Identité des Tumeurs' Program and the joint program 'Développement d'outils de diagnostic moléculaire en Cancérologie: Applications aux cancers du sein' Ministère de l'Enseignement Supérieur, de la Recherche et de la Technologie and Fédération Nationale des Centres de Lutte Contre le Cancer. The help of the Génopole Montpellier Languedoc-Roussillon is greatefully acknowledged. M.N. was supported by a doctoral fellowship from the Ligue Nationale Contre le Cancer and C.R. by funds from the Cancéropole Grand Sud Ouest.

Supplementary Information accompanies the paper on British Journal of Cancer website (http://www.nature.com/bjc).

Kallioniemi A (2002) Impact of DNA amplification on gene expression patterns in breast cancer. Cancer Res 62: 6240-6245

Inoue J, Otsuki T, Hirasawa A, Imoto I, Matsuo Y, Shimizu S, Taniwaki M, Inazawa J (2004) Overexpression of PDZK1 within the $1 \mathrm{q} 12-\mathrm{q} 22$ amplicon is likely to be associated with drug-resistance phenotype in multiple myeloma. Am J Pathol 165: 71-81

Kerangueven F, Noguchi T, Coulier F, Allione F, Wargniez V, SimonyLafontaine J, Longy M, Jacquemier J, Sobol H, Eisinger F, Birnbaum D (1997) Genome-wide search for loss of heterozygosity shows extensive genetic diversity of human breast carcinomas. Cancer Res 57: 5469-5474 Larramendy ML, Lushnikova T, Bjorkqvist AM, Wistuba II Virmani AK, Shivapurkar N, Gazdar AF, Knuutila S (2000) Comparative genomic hybridization reveals complex genetic changes in primary breast cancer tumors and their cell lines. Cancer Genet Cytogenet 119: 132-138

Loo LW, Grove DI, Williams EM, Neal CL, Cousens LA, Schubert EL, Holcomb IN, Massa HF, Glogovac J, Li CI, Malone KE, Daling JR, Delrow JJ, Trask BJ, Hsu L, Porter PL (2004) Array comparative genomic hybridization analysis of genomic alterations in breast cancer subtypes. Cancer Res 64: $8541-8549$

Lu PJ, Sundquist K, Baeckstrom D, Poulsom R, Hanby A, Meier-Ewert S, Jones T, Mitchell M, Pitha-Rowe P, Freemont P, Taylor-Papadimitriou J (1999) A novel gene (PLU-1) containing highly conserved putative DNA/chromatin binding motifs is specifically up-regulated in breast cancer. J Biol Chem 274: 15633 - 15645

Malamou-Mitsi VD, Syrrou M, Georgiou I, Pagoulatos G, Agnantis N (1999) Analysis of chromosomal aberrations in breast cancer by comparative genomic hybridization (CGH). Correlation with histoprognostic variables and c-erbB-2 immunoexpression. J Exp Clin Cancer Res 18: $357-361$

Nugoli M, Chuchana P, Vendrell J, Orsetti B, Ursule L, Nguyen C, Birnbaum D, Douzery EJ, Cohen P, Theillet C (2003) Genetic variability in MCF-7 sublines: evidence of rapid genomic and RNA expression profile modifications. BMC Cancer 3: 13

Orsetti B, Nugoli M, Cervera N, Lasorsa L, Chuchana P, Ursule L, Nguyen C, Redon R, du Manoir S, Rodriguez C, Theillet C (2004) Genomic and expression profiling of chromosome 17 in breast cancer reveals complex patterns of alterations and novel candidate genes. Cancer Res 64: $6453-6460$

Osborne RJ, Hamshere MG (2000) A genome-wide map showing common regions of loss of heterozygosity/allelic imbalance in breast cancer. Cancer Res 60: 3706-3712

Rennstam K, Ahlstedt-Soini M, Baldetorp B, Bendahl PO, Borg A, Karhu R, Tanner M, Tirkkonen M, Isola J (2003) Patterns of chromosomal imbalances defines subgroups of breast cancer with distinct clinical features and prognosis. A study of 305 tumors by comparative genomic hybridization. Cancer Res 63: $8861-8868$

Reyal F, Stransky N, Bernard-Pierrot I, Vincent-Salomon A, de Rycke Y, Elvin P, Cassidy A, Graham A, Spraggon C, Desille Y, Fourquet A, Nos C, 
Pouillart P, Magdelenat H, Stoppa-Lyonnet D, Couturier J, Sigal-Zafrani B, Asselain B, Sastre-Garau X, Delattre O, Thiery JP, Radvanyi F (2005) Visualizing chromosomes as transcriptome correlation maps: evidence of chromosomal domains containing co-expressed genes - a study of 130 invasive ductal breast carcinomas. Cancer Res 65: 1376-1383

Schroeder JA, Masri AA, Adriance MC, Tessier JC, Kotlarczyk KL, Thompson MC, Gendler SJ (2004) MUC1 overexpression results in mammary gland tumorigenesis and prolonged alveolar differentiation. Oncogene 23: 5739-5747

Stange DE, Radlwimmer B, Schubert F, Traub F, Pich A, Toedt G, Mendrzyk F, Lehmann U, Eils R, Kreipe H, Lichter P (2006) High-resolution genomic profiling reveals association of chromosomal aberrations on $1 \mathrm{q}$ and 16p with histologic and genetic subgroups of invasive breast cancer. Clin Cancer Res 12: 345 - 352

Struski S, Doco-Fenzy M, Cornillet-Lefebvre P (2002) Compilation of published comparative genomic hybridization studies. Cancer Genet Cytogenet 135: $63-90$
Teixeira MR, Pandis N, Heim S (2002) Cytogenetic clues to breast carcinogenesis. Genes Chromosomes Cancer 33: 1-16

Tirkkonen M, Tanner M, Karhu R, Kallioniemi A, Isola J, Kallioniemi OP (1998) Molecular cytogenetics of primary breast cancer by CGH. Genes Chromosomes Cancer 21: 177-184

Tsarouha H, Pandis N, Bardi G, Teixeira MR, Andersen JA, Heim S (1999) Karyotypic evolution in breast carcinomas with $\mathrm{i}(1)(\mathrm{q} 10)$ and $\operatorname{der}(1 ; 16)(\mathrm{q} 10 ; \mathrm{p} 10)$ as the primary chromosome abnormality. Cancer Genet Cytogenet 113: $156-161$

Tse W, Meshinchi S, Alonzo TA, Stirewalt DL, Gerbing RB, Woods WG, Appelbaum FR, Radich JP (2004) Elevated expression of the AF1q gene, an MLL fusion partner, is an independent adverse prognostic factor in pediatric acute myeloid leukemia. Blood 104: 3058-3063

Upender MB, Habermann JK, McShane LM, Korn EL, Barrett JC, Difilippantonio MJ, Ried T (2004) Chromosome transfer induced aneuploidy results in complex dysregulation of the cellular transcriptome in immortalized and cancer cells. Cancer Res 64: 6941-6949 